\title{
Article
}

\section{Five Ways to Wellbeing: holistic narratives of public health programme participants}

Farrier, Alan, Dooris, Mark T and Froggett, Lynn

Available at http://clok.uclan.ac.uk/19064/

Farrier, Alan ORCID: 0000-0003-4989-2209, Dooris, Mark T ORCID: 0000-00025986-1660 and Froggett, Lynn ORCID: 0000-0001-8406-6231 (2019) Five Ways to Wellbeing: holistic narratives of public health programme

participants. Global Health Promotion, 26 (3). pp. 71-79. ISSN 1757-9759

It is advisable to refer to the publisher's version if you intend to cite from the work.

http://dx.doi.org/10.1177/1757975917732352

For more information about UCLan's research in this area go to http://www.uclan.ac.uk/researchgroups/ and search for <name of research Group>.

For information about Research generally at UCLan please go to http://www.uclan.ac.uk/research/

All outputs in CLoK are protected by Intellectual Property Rights law, including Copyright law. Copyright, IPR and Moral Rights for the works on this site are retained by the individual authors and/or other copyright owners. Terms and conditions for use of this material are defined in the policies page.

\section{CLoK}

Central Lancashire online Knowledge www.clok.uclan.ac.uk

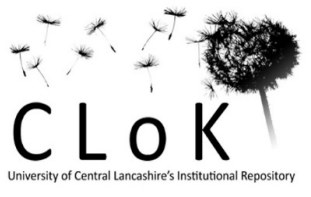


Article Type

Original Research

\title{
GLOBAL HEALTH PROMOTION
}

\section{TITLE}

\section{Five Ways to Wellbeing: holistic narratives of public health programme participants}

\author{
Authors: \\ Alan Farrier Healthy and Sustainable Settings Unit, College of Health and Wellbeing, University of Central \\ Lancashire, Brook Building, Preston PR1 2HE) - 01772895118 - afarrier@uclan.ac.uk (Corresponding Author) \\ Mark Dooris Healthy and Sustainable Settings Unit, College of Health and Wellbeing, University of Central \\ Lancashire, Brook Building, Preston PR1 2HE) - 01772893760 - mtdooris@uclan.ac.uk \\ Lynn Froggett Psychosocial Research Unit, School of Social Work, Care and Community, University of \\ Central Lancashire, Harrington Building, Preston PR1 2HE) - 01772893472 - Ifroggett@uclan.ac.uk \\ Funding: \\ This work was supported by the Big Lottery Fund [no Grant number].
}

\section{ABSTRACT}

This paper reports on a study which formed part of a qualitative process evaluation of a wellbeing programme in North West England. The study used the biographic narrative interpretive method (BNIM) to undertake and analyse data from interviews with six participants from diverse projects within the programme. This generated rich case studies and spotlighted cross-case commonalities, building understanding of how the programme achieved its effects. We present findings using the Five Ways to Wellbeing framework, presenting one abridged 'case' and summarising cross-cutting themes. We explore how BNIM gives insight into the psychosocial complexity of wellbeing, building understanding of its holistic and dynamic nature, and then highlight the flexibility, resonance and widespread appeal of Five Ways to Wellbeing. In concluding, we argue that by enabling participants to tell their own stories of participation in the different projects, we gain a more authentic understanding of the 'whole' story of how involvement has affected wellbeing. Such approaches are crucial as wellbeing becomes a central concept in global health policy and promotion.

\section{INTRODUCTION}

This paper reports on an evaluative study that used the biographic narrative interpretive method (BNIM) (1) to undertake and analyse data from interviews with participants in a wellbeing programme in North West England. In it, we present and discuss findings, and critically examine the value of BNIM in affording insight into the psychosocial complexity of well-being.

The concept of wellbeing is paradoxical, used in everyday parlance (2) whilst remaining a 'complex, multi-faceted construct that has continued to elude researchers' attempts to define and measure' (3)(p60). Despite conceptual challenges, there is burgeoning interest at a global level in exploring the potential offered by wellbeing as a new model of societal 
progress (4). Wellbeing is concerned with the condition of an individual, group or community and can be defined in relation to two contrasting perspectives - hedonic and eudaemonic. The former describes pleasure, avoidance of pain and subjective happiness, the latter focuses on human flourishing (5).

It is argued that wellbeing offers a useful concept for understanding public health, offering a more holistic approach than traditionally narrower concepts of health and illness. It considers not only individual lifestyle, but also wider social determinants requiring 'upstream' intervention (e.g. unemployment, housing) (6-8); has a strong focus on mental as well as physical health (9); incorporates objective and subjective elements (10); and - in England -resonates with Health and Wellbeing Boards and the overarching orientation of local authorities, within which the local public health function is located (11).

In 2008, the UK Government's Foresight programme commissioned the New Economics Foundation to develop a set of evidence-based actions to improve personal wellbeing. The resulting Five Ways to Wellbeing framework $(12)(p 1)$ is informed by eudaemonic and hedonic understandings:

The concept of wellbeing comprises two main elements: feeling good and functioning well.

The 'five ways' are specific actions that can be built into people's everyday lives: 'Connect' (with family/friends/colleagues/neighbours), 'Be Active' (with physical and/or other activities), 'Take Notice' (be aware of the world around you and reflect on experiences), 'Keep Learning' (for enjoyment and increased confidence), and 'Give' (creating rewarding community connections). Since its introduction, Five Ways to Wellbeing has become one of the most widely used evidence-informed frameworks in the field (7).

Target: Wellbeing (TWB) was a public health programme in North West England that ran from 2007 to 2015, funded by Big Lottery's Wellbeing Programme. Its first phase (20072012) comprised 95 projects within twelve programmes operating in localities identified through needs assessment using the Index of Multiple Deprivation (13). Projects focused on three funder-determined outcome areas: increasing physical activity (e.g. cycling/walking); encouraging healthy eating (e.g. food growing/cooking); and improving mental wellbeing (e.g. drama groups for people with mental health issues seeking employment). A quantitative impact evaluation of Phase One of TWB measured mental wellbeing, physical activity and healthier eating outcome indicators and found that the programme benefitted over 110,000 people (14). Complementing this, a qualitative process evaluation was conducted.

\section{STUDY DESIGN AND METHODS}


The Phase One process evaluation focused on process, implementation and context to increase understanding of how the portfolio was delivered and experienced, and why different approaches worked well or not so well in achieving desired outcomes (15). After gaining ethical approval through a UCLan ethics committee, it gathered data from a sample of 13 projects, chosen to ensure representation from the three overarching themes and from the three sub-regions making up the TWB geographical footprint. It used both one-toone and focus group interviews, allowing views and experiences of stakeholders to be explored, eliciting both individual perspectives and insights informed by interaction (16). This paper reports on one study undertaken as part of this evaluation, which used BNIM (1) to undertake individual interviews with six participants.

Narrative-based research emerged in the early $20^{\text {th }}$ century and are now used in most social science disciplines (17). Whilst type of data and methods of analysis can be extremely varied, a shared concern is with how stories are constructed and why they are constructed by the narrator in such a way (17). BNIM (1) is a comparatively recent method, established in the 1990s, which supports a psychosocial approach by highlighting the intersection of personal and contextual factors. Although time-consuming, Wengraf (1) suggests that analysis of three to six BNIM interviews is sufficient to allow theorisation across cases - and Sandelowski (18) suggests that a small number of interviews can produce 'empirical intimacy', fine-grained understanding of the ways in which people engage with activities designed to improve their wellbeing.

The aims of the BNIM interviews were: firstly, to enable psychosocially in-depth reflection and capture participants' stories of their involvement in TWB projects through the development of individual case studies (an illustrative example is given below); secondly, to draw out points of cross-case resonance, thus developing a nuanced understanding of how TWB achieved its effects and inform future programmes. Case studies are effective in capturing stories and articulating subjective understandings. Through generating narratives, the intention was to gain insight into the subjectivity and authenticity of participants' experiences using rich descriptions of the social worlds they inhabit $(19,20)$ and how these developed over time. By looking across cases, it is possible to see commonalities and variations in response and - consistent with realist evaluation (21) - achieve a theoretical generalisation to explain what works for whom under what circumstances.

BNIM was chosen instead of other approaches (e.g. Interpretive Phenomenological Analysis) for four reasons: firstly, it enables the interviewer to focus a specific event (in this case involvement in TWB) within the context of the interviewee's 'told' life-story and explore its effect on a life trajectory; secondly, the use of a single open question enables the interviewee to determine criteria of relevance within their narrative (thus the interviewee is not asked directly to attribute the wellbeing effects experienced); thirdly, the use of rigorous panel-based interpretation allows researchers to achieve consensus on key aspects of the interviewee's account in the context of their 'told story'; fourthly, BNIM offers safeguards against over-interpretation when considering performative dimensions (considering how the story is told in relation to the patterning or gestalt of the interview, yielding insight into how the interviewee can be expected to respond to change). 
BNIM interviews, lasting 30-60 minutes, were conducted with six participants from different types of project across the TWB geographical footprint: Preston on Wheels (PoW) (cycling); Activate (A) (walking); Impact (I) (cooking activities for fathers/children); My Journey (MJ) (drama for people with mental health issues); Diamond Lives (DL) (chair-based exercise for older people); and Grow Your Own For the Over 50s (GYO) (gardening). Participants were selected by purposive sampling, informed by liaison with project managers: four participants were male, two were female; the age range was 30-75; five participants were White British, one was Asian British.

Appreciating that personal stories have an inner logic and flow and that individuals are less likely to censor these if invited to tell them uninterrupted, according to their own system of relevance (22), BNIM interviews were framed by an open question, concerning the impact of involvement in a TWB project on the individual's life-course. This allowed participants to tell their stories at their own pace, in the order they wished, focusing on what they felt was important, free from interruption or steering. The interviewer listened to the stories and made notes, respecting the account's ordering and language. When the participant finished, the interviewer asked for elaboration on key points (in the order they were raised) by asking narrative-pointed questions. For example, when a participant stated that 'it was fun doing an exercise', the interviewer asked 'can you tell me about a particular time when you remember having fun doing this exercise?'.

Following BNIM protocols (1), the interviews were transcribed verbatim and interpretation and analysis were undertaken by a panel comprising the interviewer and two other research team members. The interviewer presented the transcript in a sequential series of 'data chunks' and, using free association, the panel then offered interpretation of each chunk and 'future-blind' conjectures on where the text would lead, speculating on the meaning of utterances and the interviewee's overt and unstated intentions. Each interpretation was regarded as provisional until significant support was gained from the panel in the context of the 'whole' interview. The resulting hypotheses were regarded as strongly founded, giving access to a richer understanding of how the project affected the interviewee. When the panel process was complete, the interviewer wrote up individual case studies, each being a chronological 'story' in which the participant's experiences could be read alongside the panel's analysis of the structure of the particular case. This enabled a focus on performance and gestalt, invaluable for speculating on unstated motivations, affects and states of mind associated with personal wellbeing, while at the same time situating them within wider contextual influences such as interpersonal relationships, organisations, and social, political and economic systems $(1,23)$. The research team then met again after the panel analysis sessions were complete to analyse the key emerging cross-cutting themes.

\section{FINDINGS}

The case studies are lengthy because of the rich detail generated, so for illustrative purposes, an abridged version of one case is included:

Reg's Story:

Pre-Print Version: Farrier, A., Dooris, M. and Froggett, L. (in press) Five Ways to Wellbeing: holistic narratives of public health programme participants. Global Health Promotion. 
Several years ago, Reg, a white male in his 50s, has a brain haemorrhage. This has a profound effect on his life in multiple ways, including him no longer coping with work as a teacher. His GP refers him to a 12-week course designed to improve health and physical activity levels. Already interested in exercise, Reg is "convinced from the outset" to participate. The course acts as a springboard to Reg joining a leisure centre, where someone mentions 'Preston on Wheels' (PoW). He meets the Project Manager, whom he likes, and joins. He has now been part of this cycling project since its early stages, attending twice a week. After a lengthy break due to winter weather, Reg makes it clear he is eager to get back on the saddle.

Although not clearly articulated, it appears that, subsequent to his brain haemorrhage, Reg has suffered from depression: he acknowledges that in his condition "It is all too easy not to put your foot outside the front door...you have to get your mind around it." One of the driving factors to attending is not wanting to let other people down.

Reg is impressed by the inclusivity of the project and its use of adaptive cycles. He thinks that the rides are "fantastic" and appears exhilarated and excited as he describes the range of locations visited. He recognises that the project is not only about riding bikes: "The thing is it's more than just the physical exercise, it's also...spiritual wellbeing, the buzz you get from actually doing it." One of his favourite aspects is seeing local wildlife, and he recounts "brilliant" experiences of viewing local birds in their natural habitat: "I come back thinking I'm really glad that I've made the effort...it does leave you...psychologically a lot better having gone to do the ride."

Reflecting on how the project manager dealt with a member's disruptive behaviour, Reg praises and speaks with enthusiasm about the lead riders, describing them as a good and skilled "peopleorientated" crowd focused on the good of the whole group. Reg speaks with pride about winning a certificate for Best Newcomer. He is definite that he will continue to participate and has begun to volunteer at another local non-cycling wildlife project.

\section{Structure of Reg's Case:}

The relational context of the project is vitally important to Reg - it is not just his physical health which benefits but also social connectivity with other participants. Part of the pull to participate regularly is a desire not to let the team down. The project allows for an exhilarating individual experience but is about more than merely riding his bike. It is a more holistic experience enabling him to connect with nature and his surroundings. Furthermore, participating in the project is enabling and transformative for Reg - he is gaining more confidence in his riding ability and recognition from the project through his award, and is now volunteering in another community project.

Five Ways to Wellbeing (12) was referred to frequently by TWB project managers. Within Reg's and other case studies, there is evidence of each element of the framework, suggesting that it is a useful framework to use in reporting cross-cutting points of resonance related to wellbeing-related findings. Considering the 'Five Ways' in turn:

\section{1. 'Connect'}

Social connectedness was the most important benefit experienced by participants in TWB projects, permeating all case studies, regardless of the thematic focus. Whilst Reg's health condition had previously prevented him from leaving the house, PoW enabled him to 
connect with his project group and the strong bonds formed further motivated his participation.

In other case studies, by building confidence, trust and skills to interact and relate, participants facing varying degrees of social isolation were enabled to share experiences and forge new friendships and networks, both with other participants and the key staff involved in their project:

I found a very interesting group of older people and tutors...that was another side of the project that...brought me into contact with...people. (GYO)

These interactions also helped strengthen community bonds with local families they had not previously had any contact with:

[We were] meeting different people and different kids. (I)

The impending end to project funding was a concern, but there was also evidence that friendships developed through participation had built up a degree of resilience and would continue:

A group of us got together and said if the walking project finished we would keep together and we would keep on walking, for the exercise and the social side of it...we've all become great friends...It's a great social get-together. (A)

\section{2. 'Be Active'}

Importantly, projects opened up opportunities for participants not otherwise physically active. Reg's story included mention of this inclusivity, highlighting peer support and adaptive bikes.

People who wouldn't necessarily be able to do any cycling are actually out cycling, which is fantastic I think, another dimension to the... activity. (PoW)

Many of the projects enabled people to be more physically active, participating in multiple diverse activities (e.g. cycling, walking, outdoor pursuits):

We all felt good whilst we were doing it...everybody was saying, you know, how well they felt after it as well. (GYO)

Being more physically active also generated a sense of accomplishment, be a drama performance or a physical activity previously thought to have been unachievable:

I've always wanted to climb that [mountain] but I've always been too fat...last year I actually climbed to the top...I was over the moon. (A)

Some of the projects combined physical activity with personal expression and creativity, offering a safe space for self-expression themselves and reintegration: 
People recovering from mental illness have certain needs... [drama is] something [we can] do in a...non-threatening environment...new things were difficult for me and I was lacking confidence...I managed to get through this... These activities enable people, it gets them back into society. (MJ)

\section{3. 'Take Notice'}

Participants described pleasure gained from engaging with their locality, articulating a exhilaration and mood improvement. In Reg's story, this was described as the "spiritual wellbeing" or "buzz," derived as much from encounters with local wildlife and new places as the physical exertion of the cycle-ride.

In the other case studies, this enhanced mood was also often understood to result from unplanned consequences beyond pre-defined wellbeing outcomes, related to enhanced awareness through engaging with local cultural assets, accessing nature and experiencing the local environment in new ways - seeing it differently and more appreciatively:

There's green parts of [the town] that I never knew existed until I started doing these walks to be honest with you. (A)

\section{4. 'Keep Learning'}

It wasn't unusual for projects to include a core focus on learning, developing knowledge, understanding and/or skills in diverse areas. These included drama, horticulture, bicycle maintenance (Reg won a 'Best Newcomer to Cycling' award at a local community event) and chair-based exercise:

...sitting in your chair raising your leg up, things like that. People used to laugh and say 'gosh, I didn't realise I could do that! (DL)

Learning-related benefits varied across projects. One example was developing parental skills for improved family relationships:

We're more close to our kids now, we spend quality time with them and play with them...family life...it's a lot better than before...so, I think we learned quite a lot. (I)

For a horticultural project participant, the learning was even more explicit:

We are all novices... without the instruction we simply would not have known how to tackle the preparation or sowing or technical things... we are absolutely dependent on guidance. (GYO)

Reinforcing this focus on learning, participants also reflected on the sense of achievement, self-development and empowerment gained through participation.

Pre-Print Version: Farrier, A., Dooris, M. and Froggett, L. (in press) Five Ways to Wellbeing: holistic narratives of public health programme participants. Global Health Promotion. 


\section{5. 'Give'}

Through gaining knowledge, skills and confidence, participants developed self-efficacy and purpose as they realised they had something to give - that their involvement mattered to other people and that they could begin to contribute. This 'giving' manifested itself through participants undertaking a positional shift to support and mentor newcomers and fellow participants. Reg had begun volunteering on another local project and this shift was demonstrated in other case studies:

I see myself now as being a volunteer...helping people to come on...I've got an awful lot out of it and I'm in a position to put something back. (MJ)

The value of giving was also demonstrated by projects' inclusivity towards new members:

... whenever we get any new ones in, we bring them right into the group... we chat to them, make them feel welcome and at home. (A)

In some cases (including Reg's), this contribution involved being more politically motivated gaining the drive and direction to make a difference in the world. Some participants demonstrated awareness of the precarious funding-state of their projects and showed a determination to take on an advocacy role:

I'm annoyed quite honestly that the...powers that be want to wash their hands of something that's as worthy as this is. (MJ)

\section{DISCUSSION}

It is argued that BNIM is particularly useful for conducting "retrospective and ongoing longitudinal process studies of complexity" $(22)(\mathrm{p} 19)$ and that this gives it particular power in revealing and elucidating transformations in people's lives. The open and emergent BNIM interviews, when analysed and written up as case studies (such as Reg's Story) revealed the impact of TWB projects and enabled different levels of influence on wellbeing to be explored. The researchers were able to see and appreciate the significance of the various psychosocial dimensions and the interrelationships between them (24): the emotional or intra-psychic (the 'spiritual buzz' derived from participation), the interpersonal (the focus on social interaction and connectivity), the cultural/institutional (the projects' peopleorientated inclusivity) and the societal (recognising the larger social impact of projects and becoming more politicised). The TWB projects studied through this psychosocial perspective showed wellbeing implicitly to be a complex quest, negotiated through informal personal relationships, networks and communities as well as the institutions that frame everyday life.

The research team observed during their evaluation that Five Ways to Wellbeing (12) was drawn on extensively by project managers. Reflecting on this, it was noteworthy that all six BNIM case studies demonstrated how TWB had addressed each of the Five Ways, regardless 
of their primary outcome area, and despite the framework not explicitly being referred to in any of the BNIM interviews. Furthermore, due to the nature of the BNIM method, these themes emerged from participants' stories with no direct prompting.

We would suggest that this is because wellbeing is essentially holistic and dynamic in nature and although the factors that promote it are sometimes unpredictable (25), Five Ways to Wellbeing provides a framework that is sufficiently flexible to be applied to multiple diverse projects.

During the course of the evaluation, the research team observed that Five Ways to Wellbeing had stronger resonance with many TWB project staff than evaluation tools focused on the specific outcome areas of mental wellbeing, physical activity and healthier eating. This may be due to wellbeing not being readily compartmentalised into neatlydefined boxes and TWB projects not easily corresponding to just one 'primary' outcome. For example, a 'healthy eating' project may also foster mental wellbeing through means of inter-personal relationships; a 'physical activity' project may enable and enhance participants' social connectedness and catalyse interest in healthy lifestyles (including food); and a 'mental wellbeing' project using horticulture may also stimulate engagement with healthy food and increase exercise levels. Furthermore, as wellbeing is experienced subjectively, projects will have different outcomes for individual participants. By analysing participants' stories, the research team was able to capture the experiential dimension of participation in TWB projects, thereby addressing some of the limitations of the quantitative evaluation - which set out to measure projects against the pre-defined 'primary' outcomes. Whereas 'experience' may be regarded as an elusive object of study, it is arguably the most important factor in promoting and sustaining engagement, and therefore accounts of participant experience are crucial in revealing a project's transformative potential.

Whilst the stories revealed both hedonic and eudaemonic perspectives (5), the latter dominated. Whilst important, pleasure appeared less significant than notions of selfdevelopment, self-realisation and a renewed sense of purpose, through people connecting with others and realising that they had something of value to contribute. The BNIM interviews were valuable in offering space for participants to recall and tell stories in more depth than would often be possible in traditional evaluations, thus allowing the intrinsically more complex eudaemonic dimension to emerge. Telling the 'whole' story also enabled researchers to obtain accounts of how participants experienced the projects that were not broken down a priori into researcher-defined categories. The gestalt of the story could then be discerned, revealing that "the whole is different than the sum of its parts" (26)(p383). This is significant for research design, as BNIM yielded profound and complex understandings of wellbeing benefits that only became visible when participants' biographical stories were analysed holistically. Whilst the small number of interviews could be considered a limitation, BNIM allows even a small number of narrative-pointed interviews to capture rich data and generate revealing case studies capable of generating cross-case theorisation $(1,18)$. 
With regard to Five Ways to Wellbeing, 'Connect' is arguably the most significant 'way'. Social interaction was crucial to all projects, with the case studies highlighting the importance of increased social capital - defined as the 'collective value of a person's social networks, which are a key aspect of mental well-being and of stronger, healthier, connected communities' (27)(p49). Social contact has long been recognised as central to wellbeing (28) and Ryan and Deci suggest that "there has been increasing appreciation...of the importance of warm, trusting and supportive interpersonal relationships for wellbeing" (5)(p154).

Whilst 'Be Active' suggests physical activity, all projects were activity-focused to a degree, so this was just as applicable to a drama project as to cycling and walking. Regular physical activity is known to be valuable for physical health, but is also associated with increased levels of mental wellbeing (29) and lower rates of depression and anxiety across all age groups (30). Furthermore, there is a growing body of evidence that engagement in creativity and the arts can make a major contribution to wellbeing (31).

'Take Notice' is most often linked to activities taking place in green spaces. This can be understood as an expansion of participants' psychogeographical awareness, whereby the environment influences emotions and behaviour (32). The strong focus on connectivity with the environment is supported by an increasing evidence base suggesting that access to nature can have multiple interconnected benefits for mental and physical wellbeing (33).

Whilst 'Keep Learning' was explicitly linked to projects with an educative focus, all projects offered scope to learn in informal and nuanced ways from activities and peers. Learning throughout life has been shown to benefit wellbeing, with effects being mediated by selfesteem, self-efficacy, sense of purpose and social integration (34).

'Give' resonated with participants' stories, which revealed emerging confidence and motivation to help others in their local community. Mental wellbeing is enhanced when an individual is able to achieve a sense of purpose and contribute to their community - and "helping, sharing, giving and team-oriented behaviours are likely to be associated with an increased sense of self-worth and positive feelings." (12)(p10).

\section{CONCLUSION}

As "wellbeing assumes centre stage in national and global policy discourse" (35)(p120), it will become increasingly important to find research approaches that can meaningfully capture both the richness of the concept and the authenticity of lived experiences. In this study, BNIM proved a highly valuable means of gathering and analysing qualitative data. Its strengths were illustrated through how it revealed all Five Ways to Wellbeing by allowing participants to tell their own stories. That all five ways are clearly visible in the case studies also validates the decision to use this particular framework, its cross-cutting perspective being congruent with BNIM's explicit whole person and whole story focus.

This evaluation has demonstrated the value of Five Ways to Wellbeing in facilitating a holistic and dynamic interpretation of the wellbeing benefits of a public health programme. 
Revisiting the psychosocial perspective within which this evaluation was framed, it is apparent that whilst the framework's primary focus is individual behaviour, this concern with 'downstream' interventions is underpinned by recognition that relationships and social context are key in shaping behaviour and that effective promotion of wellbeing requires investment in 'upstream' interventions (36). Only by addressing the circumstances in which people live and tackling wider determinants can "issues of causality, effect size and favourable conditions for sustainable behavioural change" be understood (12)(p17).

To the best of the researchers' knowledge, of the six projects in which the BNIM interviewees were involved, only PoW was mainstreamed and is still running. What is unknown is whether participants continued to experience the wellbeing benefits of projects after they ceased. Whilst practically challenging, a valuable next step would therefore be to conduct follow-on BNIM interviews several years after the interventions have finished, in order to determine whether they have integrated Five Ways to Wellbeing actions into their daily lives as a result of participation and therefore to what extent the benefits are longitudinal.

\section{REFERENCES}

(1) Wengraf T. Qualitative research interviewing: Biographic narrative and semi-structured methods. London: Sage; 2001.

(2) Kammann R, Farry M, Herb P. The analysis and measurement of happiness as a sense of well-being. In Michalos AC, ed. Citation classics from social indicators research. Dordecht, Netherlands: Springer; 2005: 279-303.

(3) Pollard E, Lee P. Child well-being: A systematic review of the literature. Soc Indic Res 2003; 61(1): 9-78.

(4) Anderson P, Cooper C, Layard R, Litchfield P, Jane-Llopis E. Well-being and global success: A report prepared by the World Economic Forum Global Agenda Council on Health \& Well-being. Geneva: World Economic Forum; 2012.

(5) Ryan RM, Deci EL. On happiness and human potentials: A review of research on hedonic and eudaimonic well-being. Annu Rev Psychol 2001; 52: 141-166.

(6) Huppert F. Psychological well-being: Evidence regarding its causes and its consequences. London: Foresight; 2009.

(7) Aked J, Thompson S. Five ways to wellbeing: New applications, new ways of thinking. London: New Economics Foundation; 2011.

(8) Marmot M. Fair society, healthy lives: Strategic review of health inequalities in England post-2010. London: The Marmot Review; 2010. 
(9) Government Office for Science. Foresight mental capital and wellbeing project. Final project report. London: Government Office for Science; 2008.

(10) Walker P. Wellbeing: on public health and wellbeing. In Walker P, John M, eds. From public health to wellbeing: the new driver for policy and action. 1st ed. Basingstoke:

Palgrave Macmillan; 2012: 1-20.

(11) HM Government. Healthy lives, healthy people: Our strategy for public health in England. London: Department of Health; 2010.

(12) Aked J, Marks N, Cordon C, Thompson S. Five ways to wellbeing: A report presented to the Foresight Project on communicating the evidence base for improving people's wellbeing. London: New Economics Foundation; 2008.

(13) Office for National Statistics. Index of Multiple Deprivation (IMD). 2007 [cited 2017 February 6]. Available from:

https://data.gov.uk/dataset/index of multiple deprivation imd 2007

(14) Swarbrick K, Jones A, Perkins C. Target: Wellbeing evaluation. Final report. Liverpool: North West Public Health Observatory; 2012.

(15) Lamont T, Barber N, de Pury J, Fulop N, Garfield-Birkbeck S, Lilford R et al. New approaches to evaluating complex health and care systems. BMJ 2016; 352: i154.

(16) Wilkinson S. Analysing focus group data. In Silverman D, ed. Qualitative research. $3^{\text {rd }}$ ed. London: Sage; 2011: 168-184.

(17) Kohler Riessman, C. Narrative Methods for the Human Sciences. Thousand Oaks: Sage Publications; 2008.

(18) Sandelowski M. Reembodying qualitative inquiry. Qual Health Res 2002; 12(1): 104-115.

(19) Silverman D. Doing qualitative research: A practical handbook. $4^{\text {th }}$ ed. London: Sage; 2013.

(20) Denzin NK, Lincoln YS. The landscape of qualitative research. London: Sage; 2008.

(21) Pawson R, Tilley N. Realistic Evaluation. London: Sage; 1997.

(22) Wengraf T. Life-histories, lived situations and ongoing personal experiencing. The biographic-narrative interpretive method: BNIM interviewing and interpretation. (Version 8.02b). 2008 [cited 2017 Feb 6]. Available from: http://learningaffordances.wikispaces.com/file/view/BNIM+GUIDE+8-02bn+short.doc

(23) Froggett L. Love, hate and welfare: psychosocial approaches to policy and practice. Bristol: Policy Press; 2002. 
(24) Froggett L. Psychosocial research. In Becker S, Bryman A, Ferguson H, eds.

Understanding research for social policy and social work: themes, methods and approaches. Bristol: Policy Press; 2012.

(25) Dodge R, Daly A, Huyton J, Sanders L. The challenge of defining wellbeing. International Journal of Wellbeing 2012; 2(3): 222-235.

(26) Heider GM. More about Hull and Koffka. Am Psychol 1977; 32(5): 383.

(27) HM Government and Department of Health. New horizons: Confident communities, brighter futures. A framework for developing well-being. London: Department of Health; 2010.

(28) Bacon N, Brophy M, Mguni N, Mulgan G, Shandro A. The state of happiness: Can public policy shape people's wellbeing and resilience? London: The Young Foundation; 2010.

(29) Callaghan P. Exercise: A neglected intervention in mental health care? J Psychiatr Ment Health Nurs 2004; 11: 476-483.

(30) Biddle SJH, Ekkekakis P. Physically active lifestyles and well-being. In Huppert FA, Baylis $\mathrm{N}$, Keverne B, eds. The science of well-being. Oxford: Oxford University Press; 2006: 141170.

(31) Hartwell H. Arts and health. Perspect Public Health 2013; 133(1): 2.

(32) Debord G, Nues LL. Introduction to a Critique of Urban Geography. Les Levres Nues 1955;6:23-27.

(33) Maller C, Townsend M, Pryor A, Brown P, St Leger L. Healthy nature healthy people: "contact with nature" as an upstream health promotion intervention for populations. Health Promot Int 2006; 21(1): 45-54.

(34) Hammond C. Impacts of lifelong learning upon emotional resilience, psychological and mental health: fieldwork evidence. Oxf Rev Educ 2004; 30(4): 551-568.

(35) La Placa V, McNaught A, Knight A. Discourse on wellbeing in research and practice. International Journal of Wellbeing 2013; 3(1): 116-125.

(36) Bharmal N, Derose KP, Felician M, Weden MM. Understanding the Upstream Social Determinants of Health. Santa Monica, CA: RAND Health; 2015 [cited 2017 Feb 6]. Available from:

https://www.rand.org/content/dam/rand/pubs/working papers/WR1000/WR1096/RAND WR1096.pdf 